\title{
pro.posições
}

e-ISSN 1980-6248

http://dx.doi.org/10.1590/1980-6248-2016-0147

ARTIGOS

\section{Criação poética e currículo da diferença}

\section{Poetic creation and curriculum of difference}

Angélica Vier Munhoz (i)

Máximo Daniel Lamela Adó (ii)

(i) Universidade do Vale do Taquari - UNIVATES, Lajeado, RS, Brasil, angelicavmunhoz@gmail.com.

(ii) Universidade Federal do Rio Grande do Sul, UFRGS, Porto Alegre, RS, Brasil, maximo.lamela@gmail.com.

Resumo: Este ensaio propõe atuar com as forças artísticas de um currículo a partir dos trabalhos de Sophie Calle e Georges Perec. De modo a embaralhar arte e vida, ambos os autores se prestam a um movimento de reduções, de subtrações tendo por base um minimalismo brutal e uma simplicidade crua. Nessa medida, tomada por ideias oulipianas e, em meio ao pensamento de Bachelard, busca-se um currículo poeticamente inventariado, suspendendo as definições, as verdades, os julgamentos, os quadros de referência, as atitudes preformatadas. Trata-se de um exercício que deseja portar um falar de coisas comuns do cotidiano, do trivial e por vezes evidentes, mas que, no entanto, raramente recebem nossa atenção. Assim, mais do que qualquer outra coisa, pretende-se pensar em um currículo que se efetuaria no encontro com diferenças tornadas visíveis, produzidas por impressões sensíveis que se repetem singularmente a cada experiência.

Palavras-chave: diferença, Bachelard, Sophie Calle, Georges Perec

Abstract: This paper discusses the artistic forces of a curriculum by considering the works of Sophie Calle and Georges Perec. By intertwining art and life, both authors lend themselves to a movement of reductions and subtractions through brutal minimalism and crude simplicity. In this sense, amidst Oulipian ideas and Bachelard's thought, the paper advocates a poetically inventoried curriculum, which suspends definitions, truths, judgments, reference frames, pre-formed attitudes. It is an exercise intended to trigger a conversation about ordinary, trivial, sometimes evident, daily things that seldom draw our attention. Thus, more than anything, the paper aims at thinking about a curriculum that would work in the encounter with differences that were made visible, produced from sensitive impressions that have been singularly repeated in every experience.

Keywords: difference, Bachelard, Sophie Calle, Georges Perec 


\section{pro.posições}

http://dx.doi.org/10.1590/1980-6248-2016-0147

\section{$e$-ISSN 1980-6248}

\section{Introdução}

Com Gaston Bachelard (1989) podemos dizer que é necessário romper com alguns hábitos da pesquisa, caso queiramos estudar os problemas propostos por uma imaginação poética. Nós associamos essa afirmação ao interesse em propor uma leitura poética das composições de um currículo. Bachelard está se referindo aos hábitos da pesquisa filosófica, especialmente aquela voltada aos temas fundamentais da filosofia das ciências. Esses hábitos estão relacionados à concepção de que um pensamento científico deve ser desenvolvido mediante uma concatenação de ideias correlacionadas, e que uma nova ideia, necessariamente, tem de integrar um corpo de ideias já aceitas. No entanto, uma filosofia da poesia, por assim dizer, antes de se dobrar na relação que haveria de ser extraída e construída de uma concatenação de ideias já aceitas, volta-se para a imagem poética que é, com efeito, variacional (Bachelard, 1989). Uma filosofia da poesia reconhece que o ato poético não tem passado, ao se constituir como imagem que provém de imaginação poética. Desse modo, afirma Bachelard (1989):

É necessário estar presente, presente à imagem no minuto da imagem: se há uma filosofia da poesia, ela deve nascer e renascer por ocasião de um verso dominante, na adesão total a uma imagem isolada, muito precisamente no próprio êxtase da novidade da imagem. (p. 01)

Enfatizando essa ideia, Bachelard (1989) diz que o poeta não confere o passado da imagem que, de algum modo, constituiu a poesia, no entanto, esse passado se enraíza imediatamente no leitor. Em outra passagem diz que em uma "imagem poética a alma afirma a sua presença (p. 6) ", colocando-nos diante da ideia de que a imagem poética é uma emergência da linguagem que antecipa, em efeito, a linguagem significante. Uma imagem poética pode sancionar a imprevisibilidade da palavra, doando, em sua própria materialidade, um modo de zombar das censuras que sempre advêm do já conhecido. Com isso, a produção de uma imagem poética se desenvolve como um processo de composição do próprio corpo da linguagem. Processo esse que se aproxima de uma relação com uma aprendizagem de liberdade. É preciso, porém, pensar liberdade como uma suspensão de definições reducionistas, de classificações e julgamentos em relação à própria aprendizagem, ao aprendente e ao aprendido. Tal concepção pode estar associada a uma experiência com processos, objetos, pessoas, situações em que a ideia de liberdade se apresenta como uma potência do ainda não conhecido, não vivido, não experimentado. 


\section{pro.posıções}

$e$-ISSN 1980-6248

http://dx.doi.org/10.1590/1980-6248-2016-0147

Tal questão, assim colocada, faz com que se entenda a criação artística como um fenômeno de responsabilidade e flerte com o porvir de uma nova realidade.

Para compor com a ideia de operar com as forças artísticas de um currículo, ou seja, forças que se prestam a composições com o que nos é indiscernível, mas nos toca como influência anímica, escolhemos os trabalhos artísticos e literários de Sophie Calle e Georges Perec.

Embaralhar arte e vida parece ser o propósito dos projetos artísticos e literários de Sophie Calle e Georges Perec. Talvez pudesse ser também o propósito para se pensar um currículo. Operar pela força artística de um currículo por meio do qual ele se mistura à vida. Trata-se de articular a dimensão poético-criadora das artes aos domínios sedimentados do currículo, de modo a misturar os códigos, descartar as intenções originais, tomar os gestos como passagens de sentidos singulares e contínuos, em um mínimo que é também o seu excesso.

Nessa medida, tomada pelas intenções de Sophie Calle, efetuar um currículo pelo movimento de reduções, de subtrações da presença, de noção de ausência a partir de um minimalismo brutal e de uma simplicidade crua.

De outro modo, mas com procedimentos irmanados, atuar com um currículo poeticamente inventariado, em que as produções de Georges Perec nos servem como exercício ecfrástico, ao transpor imagens sonoras, visuais, plásticas, entre outras, em textos. Trata-se de um exercício que deseja portar um falar de coisas comuns do cotidiano, do trivial e por vezes evidentes, mas que, no entanto, raramente recebem nossa atenção.

Trata-se de articular uma relação entre os procedimentos oulipianos de Sophie Calle e Georges Perec aos movimentos compositivos de um currículo. São oulipianos os movimentos e os procedimentos operados pelo OuLiPo (Ouvroir de Littérature Potentielle), sigla que pode ser traduzida como Atelier de Literatura Potencial. O OuLiPo é um grupo de investigadores de várias áreas que criam restrições para elaborar criações textuais, procurando elevar a linguagem escrita a uma ordem potencial. Essas restrições são tidas como liberadoras, por exigir novas articulações e combinações das linguagens e seus meios. 


\section{pro.posıções \\ $e$-ISSN 1980-6248}

http://dx.doi.org/10.1590/1980-6248-2016-0147

\section{Sophie Calle, a dimensão estética da experiência e o currículo}

Calle se vale de experiências pessoais de vida para a criação de seu trabalho. Contudo, não é de sua vida que falam as obras, mas de uma vida, um devir impessoal, pois como ela mesma nos lembra, "não é de minha vida que se trata, não sou o tema principal" (Molina, 2009, n.p.). É de uma vida comum que se ocupa a artista, dos gestos cotidianos de uma vida. Dos gestos mínimos atravessados por um corpo-experiência. É por essa via que nos aproximamos dos gestos produzidos em um currículo. Das diferentes formas de produzir os mesmos gestos no currículo. Da experiência de vida de um currículo. De um corpo como afirmação da experiência de um currículo.

Tomando como ponto de partida deste ensaio a obra L'bôtel, realizada pela artista em 1981, buscamos aproximar tal obra de um pensamento de currículo sem, contudo, analisar o trabalho da autora ou mesmo delinear exaustivamente a referida aproximação. Talvez a pretensão seja, tão somente, inventariar alguns elementos para pensar o cotidiano de um currículo ao modo minimalista de Sophie Calle.

L'bôtel, da mesma maneira que outras obras da autora, configura-se como uma postura singular como estratégia artística. Partindo de um encontro entre a dimensão estética e a ordinária da experiência, Calle as toma como inseparáveis. Em tal obra, a artista arranja um emprego de camareira em um hotel em Veneza para conhecer os hóspedes através dos objetos que eles carregavam consigo em suas viagens. Responsável pela limpeza e pela organização de 12 quartos, Calle, na ausência dos hóspedes, observa e fotografa os pertences deles, tentando recompor seus hábitos de vida. "Durante as minhas horas de camareira, eu examinei os efeitos pessoais dos viajantes, os signos da instalação provisória de certos clientes, suas sucessões em um mesmo quarto. Eu observei os detalhes de vida que me permaneciam estrangeiros" (Calle, 1984, p. 9).

Em vista disso, a artista observa uma diversidade de práticas e inventaria os comportamentos, prestando atenção nos mínimos detalhes, abandonando os clichês, o demasiadamente visível. O que intriga Calle é o modo como os pequenos detalhes cotidianos podem tornar-se estrangeiros (Sheringham, 2008). Sophie Calle não está interessada nas histórias de vida daquelas pessoas, nem em encontrar essências ou identidades, mas quer 


\section{pro.posıções}

$e$-ISSN 1980-6248

http://dx.doi.org/10.1590/1980-6248-2016-0147

"registrar quais são os seus modos de comportamento graças aos quais nós nos apropriamos e personalizamos um espaço no qual habitamos temporariamente" (Sheringam, 2008, p. 157).

Assim, as experiências vividas por Sophie Calle podem ser vistas como momentos de uma vida atravessada por sensações extraídas do cotidiano, lá onde a vida acontece, onde o ordinário se faz presente, onde de fato existimos. Lembra-nos Calle (2009) de "o que diferencia muitos de meus trabalhos é o fato de que eles são também a minha vida”.

Contudo, tais espaços, comumente, são marcados por uma monotonia tecida por linhas molares e segmentações. Como adentrar esses espaços cotidianos de outros modos?

Tomemos aqui o espaço do currículo. Tal como nos lembram Corazza Tadeu (2003), o currículo é território da verdade, do sujeito, da moral e da vontade de poder. As escolhas por determinado conhecimento ou verdade não são isentas de valorações, mas são produções que resultam de um campo de forças e de vontade de poder. "Um currículo é sempre uma imposição de sentidos, de valores, de saberes, de subjetividades particulares. É sempre uma escolha forçada, para nos valermos da força de um oxímoro" (Corazza \& Tadeu, 2003, p.55).

O currículo vive seus excessos e se alimenta de forças que passam pelo comum, em meio a uma imensa coleção de nomes, datas, lugares, fórmulas, fatos, verdades. O excesso de imagens ininterruptas, marcas da contemporaneidade, impede a imaginação e remete a uma saturação do olhar. Perdemos a experiência da história, a lentidão, a captura do olhar, o tempo da vida vivida. A experiência em um currículo reduz-se, desse modo, ao mínimo de sentido ou ao sentido do instante, o que seria quase uma ausência da experiência. Movidos pela ciência e pela técnica, abdicamos do movimento de experimentar o mundo e experienciar a si mesmo.

Todavia, a experiência de um currículo pode encontrar-se em meio à imanência dos acontecimentos e emergir em uma lentidão capaz de capturar as mínimas nuances do vivido. Trata-se de jogar o suposto simplório cotidiano ao mistério das coisas ainda não efetivadas. Um olhar, uma microexperiência de deslocamento naquilo que parece mais domesticado pela maquinaria contemporânea dos sentidos. Ao trabalhar com a matéria de um vivido, o currículo se põe a registrar signos de memória que, capturados, contêm a marca do reconhecível, do cognoscível, daquilo que se presta ao reconhecimento da cognição. Como pensar o currículo como experiência de algo que subsiste ao já dado, que resiste a um estado virtual, não representável? 


\section{pro.posıções}

$e$-ISSN 1980-6248

http://dx.doi.org/10.1590/1980-6248-2016-0147

Arremessar o currículo ao plano de pensamento no qual as possibilidades de entrecruzamentos podem ser pensadas em um exercício de encontro das diferenças, a partir de um signo que provoca na imaginação forças antes desconhecidas, forças que ultrapassam a imaginação. "Eu preciso de um vasto espaço para andar atrás de voos minúsculos", nos lembra Lhansol (1988, p.103).

O currículo carrega essa potência, um espaço-tempo arrancado das coordenadas e que, nos aproximando de Deleuze, poderia "arrastar consigo um fragmento de céu, de paisagem ou de apartamento, um retalho de visão, com o qual o rosto se compõe em poder ou qualidade" (Deleuze, 2009, p. 161).

Bachelard (1989), ao pensar uma poética do espaço, nos sugere ultrapassar a lógica normal para se conseguir viver "o que há de grande no pequeno" (p.159), já que o grande pode ser extraído do pequeno. Minorar, miniaturizar é concentrar, tornar mais intenso. "Possuo tanto melhor o mundo quanto mais hábil for em miniaturizá-lo" (p.159). Investigar as imagens simples, surpreender-se com a poética da casa, como instrumento de proteção para a alma humana, partindo dos valores da casa dos homens (cabanas) e das coisas (gavetas, armários e cofres), dos ninhos e das conchas, dos cantos, até chegar aos espaços da imensidão e da miniatura, do aberto e do fechado, e, por fim, ao valor ontológico das imagens (Bachelard, 1989). Tal qual nos sugere Bachelard (1989), colocar-se no plano da imaginação para espantarse, ver algo de novo e, ao olhar para ele, espantar-se novamente com algum pormenor.

A coisa e a percepção da coisa são uma só e mesma coisa, uma só mesma imagem, mas referida a um ou a outro dos dois sistemas de referência. A coisa é a imagem tal com ela é em si, tal como se refere a todas as outras imagens das quais sofre integralmente a ação e sobre as quais reage imediatamente. Mas a percepção da coisa é a mesma imagem referida a uma outra imagem especial que a enquadra e que só tem dela uma ação parcial e só reage a ela imediatamente. $\mathrm{Na}$ percepção assim definida nunca há outra coisa ou mais do que na coisa: pelo contrário, há menos [ênfase no original]. (Deleuze, 2009, p. 104)

Nesse sentido o que interessa é o campo da experimentação e não da linearidade, a possibilidade experimental do pensamento. Eliminar o perceptível demais, o excessivo demais, para então perceber. "Eliminar tudo o que é dejeto, morte e superfluidade ... tudo o que enraíza alguém (todo mundo) em si mesmo" (Deleuze \& Guattari, 1997, p.73).

Assim, viver de outra forma o currículo implicaria em colocar em xeque as suas verdades, interromper o seu cotidiano, os quadros de referências, as atitudes preformatadas. 


\section{pro.posições}

http://dx.doi.org/10.1590/1980-6248-2016-0147

\section{$e$-ISSN 1980-6248}

Mais do que isso, implicaria em "desperdiçar" o tempo e encontrar a dimensão política dos pequenos gestos, das impressões menores.

Por isso, aproximar um pensamento de currículo da estética de Sophie Calle se efetuaria por meio da criação de uma fresta sutil entre vida e arte, na mistura das fronteiras entre o factual e o ficcional. Entre a realidade e a ficção não há um compromisso com a verdade, com os fatos, pois os gestos podem ser inventariados. Contudo, nessa confusão proposital entre fato e ficção, operada pela artista, a ficção não se opõe à realidade, "a ficção não se engendra e não se desenvolve a não ser como o instrumento de uma experimentação afetiva, de uma exploração dos pontos sensíveis da vida" (Zourabichvili, 2005, p. 1.318).

A obra de Sophie Calle não se constitui em um plano prévio, estratificado, mas em um roteiro no qual os movimentos que formam determinado gesto possam ser repetidos, de modo que a cada repetição seja possível ver elementos mínimos, extraídos de um jogo de perícia. Talvez também se pudesse extrair de um currículo tais elementos, colocando-o em descompasso, diagramando suas forças na contramão da busca de definições, reconhecimentos, interpretações. Assim, mais do que qualquer outra coisa, um currículo se efetuaria no encontro com diferenças tornadas visíveis, produzidas a partir de impressões sensíveis que se repetem a cada experiência provocada por forças desconhecidas.

Um currículo como um miniacontecimento, menor, minúsculo, que se conecta a um devir imperceptível, operando por dentro, pelo meio. Extenuar as potencialidades do espaço, dissipar a representação, a imagem pronta. Apenas experimentar algo e esgotar o seu possível.

Ao modo de Sophie Calle, poderíamos pensar em um currículo que opera amputando, subtraindo alguma coisa, algum elemento para fazer aparecer algo diferente. O que talvez seja retirado são os elementos do poder, da representação, da normalização, da codificação, da institucionalização. Nesse sentido não é apenas a matéria de um currículo que se modifica, mas também a sua forma que cessa de ser representada. Colocar o currículo em variação contínua, submetê-lo a um tratamento menor para reencontrar as potencialidades de vida e pensamento. Tomar o menor como prenhe de possibilidades, de uma potência grávida do novo, do irrepetível, do irreversível, mesmo que retorne sempre. De certo modo, um tratamento de precisão cirúrgica, restando apenas afetos e velocidades. 


\section{pro.posıções}

$e$-ISSN 1980-6248

http://dx.doi.org/10.1590/1980-6248-2016-0147

Aí parece residir a originalidade do procedimento de Calle. Minorar para liberar devires de uma vida. No caso da aproximação de Calle com este artigo, minorar para encontrar a força artística de um currículo. Afinal, como nos lembra Vila-Matas (2011), "só as sensações mínimas e de coisas pequeníssimas são as que vivo intensamente" (p.68).

\section{Georges Perec, o espaço e o currículo}

$\mathrm{Na}$ última frase do Prólogo de Espèces d'espaces. Journal d'un usager de l'espace, livro de Georges Perec publicado em 1974, podemos ler que viver é passar de um espaço a outro, fazendo o possível para não esbarrar em nada. Parece uma definição bastante simples do viver. No entanto, há nessa definição simples uma tópica que podemos ver dimensionada no decorrer do livro e, também, da literatura de Perec, que nos interessa para pensar um currículo da diferença, qual seja: a da ideia de que, no viver, deixamos passar uma dimensão de experiência vital e vivencial dos espaços que frequentamos e dos espaços que nos frequentam.

Nesse livro, que parece ser um conjunto disperso de anotações, Georges Perec afirma não querer abordar o tema do espaço como um vazio, mas justamente o que há ao seu redor; o seu dentro. Mas nesse dentro, que ele explora por meio de sua escrita, não há muita coisa, talvez o nada, o impalpável, o imaterial, a extensão, o exterior e o que é exterior a nós. Este espaço, que poderia ser entendido como o meio pelo qual nos deslocamos, tem se multiplicado, fragmentado, diversificado, virtualizado. O espaço do qual ele se interessa seria, então, o de nossa proximidade, como o da cidade, dos corredores da escola, da nossa casa.

Vivemos nesses espaços e isso parece evidente. Quem sabe isso deveria ser evidente, nos diz Perec (1974). Mas não o é, pois o viver se constitui, também, pelo desvio, e pela tentativa de não esbarrar em nada. Isso posto, podemos evidenciar a ideia de que viver os espaços não os torna evidentes, não são evidentes, mesmo quando cotidianamente presentes. Porque, para que sejam evidentes, é necessário tornar os seus entornos, as suas margens, visíveis e manifestas em suas singularidades.

Assim, Perec pensa o espaço como um modo de fazê-lo viver em seus textos. Ou melhor, escreve-os; faz da escrita espaço instaurado. Os espaços de Perec são, em muitos de 


\section{pro.posıções}

$e$-ISSN 1980-6248

http://dx.doi.org/10.1590/1980-6248-2016-0147

seus textos, personificados como personagens de uma escrita que se auto-habita. Escreve os espaços em que, eles mesmos, atuam como personagens; os faz vivíveis.

Em Espèces d'espaces começa por habitar o espaço de uma folha em branco. A página, para Perec, "não é um suporte, não é uma folha de papel, também não é uma das caras dessa folha: ela é o ato de habitar a folha, o percurso do escritor, e esse percurso consiste em criar brancos" [ênfase no original] (Pino, 2006, p.125). Para criar brancos, é necessário criar margens, pois a atividade do escritor seria a de criar brancos no sentido de escrever de modo a possibilitar que o leitor tenha espaço para sua escritura. Não seria esse, também o espaço de uma aula e a tarefa do professor personificando um currículo da diferença?

No sentido anteriormente apontado, a tarefa de um currículo da diferença seria a de criar espaços, ao criar margens. E esses, potencialmente habitáveis e realizadamente habitados, a sua vez, instauram possibilidades para a criação de novas margens.

Nesse movimento de escrever os espaços habitando-os, instaurando-os no fazer da escritura, Georges Perec chama atenção para uma cegueira a respeito daquilo que nos constitui, ou seja, uma cegueira com relação à nossa cotidianidade. Com isso, evoca um dispor-se a observar o que nos é estrangeiro, tornando visível o estrangeiro em nós; o infraordinário e o endótico, antes que o exótico. E nos parece - como diz Cláudia Amigo Pino (2006), ao escrever sobre Perec - que "é necessário ver a nossa cotidianidade, porque ela está escapando de nossas mãos. Devemos olhar para esse espaço porque corremos o risco de perdê-lo” (p. 124), e essa perda se dá pela insistente renúncia do que não seja ideia preconcebida.

E esse é, também, o movimento do currículo da diferença. Ele se vale de procedimentos como os de Georges Perec e Sophia Calle, para dar à vista o que ela ainda não conhece do conhecido.

Fazer listas, inventariando o que pode ser visto, como fez Perec em um livro publicado em 1975 (Tentative d'épiusement d'un lieu parisien), onde propõe descrever, em anotações do presente, o que se passa no recorte e no ponto de vista que alcança sentado na mesa de um bar [Café Tabac, Café de La Mairie, Café Fontaine] na Place Saint-Sulpice entre os dias de 18 a 20 de outubro de 1974. Sua proposta era a de escrever certa totalidade da vida cotidiana, tentando anotar o que se nota, o que acontece quando não acontece nada. Sua descrição funcionou como 


\section{pro.posições}

$e$-ISSN 1980-6248

http://dx.doi.org/10.1590/1980-6248-2016-0147

uma espécie de inventário de cenas ou coisas vistas. Mas, também, como um exercício de tornar evidente a impossibilidade de contar tudo o que acontece em um ponto do mundo.

Ao escrever seu cotidiano, num exato ponto geográfico, Perec acaba por evidenciar, num movimento autobiográfico, a possibilidade da escrita e a impossibilidade da descrição realista. Ou seja, tal impossibilidade satura o real, tornando seu gesto um ato hiperreal e fazendo com que a escritura seja a possibilidade de se lançar num exercício que a converte em uma tarefa inesgotável.

Tudo isso funciona como se fosse um exercício especular em que, diante do espelho ou de um retrato, se tentasse alcançar uma identidade. Não é o visto que importa, pois se trata da presença de uma ausência neste gesto a importância está no movimento da busca.

No exercício de evidenciar o mundo observado há uma atitude poética com a existência, e essa atitude se presta a dar um contorno à variação contínua de uma identidade. É isso que nos interessa observar para a composição e a leitura de um currículo, aquilo que se presta a dar o contorno de nossas identidades. Pois

o currículo é lugar, espaço, território. O currículo é relação de poder. O currículo é trajetória, viagem, percurso. O currículo é autobiografia, nossa vida, curriculum vitae: no currículo se forja nossa identidade. O currículo é texto, discurso, documento. O currículo é documento de identidade. (Tadeu, 2011, p. 150)

No entanto, precisamos destacar que esse contorno dado às identidades é resultado de uma escritura que se apresenta como um traço da imaginação pública, alinhavado como uma rede discursiva do que circula sobre o social como possibilidade de definir o presente.

Essa escritura se comporta como autobiográfica, por admitir as singularidades de cada leitor e de cada leitura, no entanto, ela é conformada por um atravessamento do coletivo. Perec, ao escrever $W$ ou le Souvenir d'enfance, publicado em 1975 - livro reconhecidamente autobiográfico -, se impõe uma regra importante: excluir todas as lembranças individuais e dar preferência ao coletivo e ao banal. É como dizer, com Jean-Luc Nancy (1974), que se trata de um gesto singular plural; uma produção sempre relacional entre a singularidade de um sujeito e a coletividade do social. Assim, interessa-nos pensar as proposições curriculares deste mesmo modo, ou seja, como singularidades coletivas que se desdobram em didáticas e se atualizam em aulas. 


\section{pro.posições}

$e$-ISSN 1980-6248

http://dx.doi.org/10.1590/1980-6248-2016-0147

A produção literária de Georges Perec se alinhava como uma apropriação explícita e enfatiza a citação como criação. Faz com que a produção de outros autores se apresente como uma repetição que se prolifera como diferença. E, assim, faz de si um leitor que se torna escritor. Apropriando-se da leitura como escrita, ao operar uma repetição deliberadamente anacrônica, desautoriza o discurso de original e cópia. Desse modo faz com que os dados de arquivos não entrem no texto, produzindo uma relação coadunada a um real histórico que repetiria, por semelhança, o mesmo, pois utiliza esses dados, deslocando-os de seus centros de atenção ou suas ancoragens referenciais, fazendo com que retornem como potência diferida.

Quando se trata de um arquivo textual que retorna como citação, este perde o caráter funcional para se tornar fenômeno de correlação, em que o que importa é a força que o desloca e o explora, não mais como parte de um todo referido e representado, mas por seu caráter disperso e desobediente, como presença coexistente e ativa de um novo campo de forças.

Esse procedimento interessa ao campo educacional, pois permite fazer da leitura de autores importantes e canônicos no rol de escolhas curriculares, não modelos a serem decalcados, mas experiências de leitura que possam repercutir em escritura.

$\mathrm{Na}$ dimensão estética do cotidiano perequiano, parece ocorrer um efeito de détournement, ou seja, de uma potente trama de empréstimos que toma procedimentos como o pastiche e a colagem para a construção de objetos textuais e visuais carregados de atravessamentos; tudo em simultaneidade. A política aí instaurada está em sair de um cenário recorrente por ele mesmo. Ao apropriar-se da cena ou do trecho citado, ocorre uma espécie de transposição cultural que entende a criação como um processo de repetição com diferença.

Georges Perec se utiliza de outras produções artísticas não como modelos, mas matéria para suas próprias produções. Tudo que o afeta no âmbito das artes, da filosofia, das ciências lhe serve de motivo para uma nova produção. Nesse sentido, Perec parece estar tematizando a relação que haveria entre cópia e modelo. As obras, os artistas e os autores a que Perec se associa por eletividade funcionam como figuras de estilo. Quando escreveu Les choses, sua primeira obra publicada, admitiu que foi a leitura de Mythologies, de Roland Barthes, e de Education Sentimentale, de Flaubert, que lhe serviu de matéria; em Un homme qui dort indica a leitura de Melville e Kafka; em Je me souviens é a obra I remember, do artista americano Joe Brainard. 


\section{pro.posições}

$e$-ISSN 1980-6248

http://dx.doi.org/10.1590/1980-6248-2016-0147

Como uma força que move novos estilos e formas, interessa-nos tomar as produções perequianas e seus procedimentos de criação para a prática docente, produção de pesquisas e didáticas, pois as produções de Perec não são lineares, mas disformes. A cada nova produção há um modo de atuar. Não há um estilo fixo, a não ser que o estilo seja, justamente, a impossibilidade de constituir um estilo. Por meio de uma espécie de geometria hipertextual, ele desestabiliza centralidades modelares e dissemina a ideia de produzir heterogeneidades por meios heterogêneos.

\section{Conclusão}

Pensar o currículo a partir dos movimentos artísticos e literários de Sophie Calle e George Perec talvez possa nos servir para inventariar alguns elementos do currículo em meio às suas possibilidades de criação. Assim sendo, um currículo pode vazar pelas frestas e rachaduras que desestabilizam seus alicerces e compor-se de gestos singulares e poéticos que permitam experimentar uma parcela de intensidade ainda não vivenciada ou uma pequena sensação que não se prestou ao esgotamento. Ao invés de acréscimos e acumulações, propor uma espécie de esvaziamento da regularidade, do conteúdo, dos resultados, dos territórios codificados. Afinal, em uma ordem imanente, quando promovemos um caráter necessário ao que se efetiva, tudo é necessário. Disso ocorre que, na fluência da vida, e de um currículo, podese assumir, sempre, uma potência positiva, alegre e, portanto, criadora. 


\section{pro.posıções}

$e$-ISSN 1980-6248

http://dx.doi.org/10.1590/1980-6248-2016-0147

\section{Referências}

Bachelard, G. (1989). A poética do espaço. Rio de Janeiro: Martins Fontes.

Calle, S. (1998). L’hôtel. Arles: Actes Sul.

Calle, S. (2009). Sophie. Cuide cuide de você. Recuperado em 14 julho de 2009, de http://www.videobrasil.org.br/sophiecalle/.

Corazza, S., \& Tadeu, T. (2003). Composições. Belo Horizonte: Autêntica.

Deleuze, G. (2009). A imagem-movimento (Cinema 1). Lisboa: Assírio e Alvim.

Deleuze, G.\& Guattari, F. (1997). Milplatôs: capitalismo e esquizofrenia (Vol. 4.). São Paulo: Editora 34.

Lhansol, M.G. (1988). Da sebe ao ser. Porto: Edições Rolim.

Molina, C. (2009). Carta de ex-namorado motiva exposição de Sophie Calle em São Paulo. Folha de S. Paulo. Recuperado em 14 julho de 2015, de http://cultura.estadao.com.br/noticias/geral,carta-de-ex-namorado-motiva-exposicaode-sophie-calle-em-sp,400772

Nancy, J. (1974). Ser singular plural. Madrid: Arena.

Perec, G. (1974). Espèces d'espaces. Journal d'un usager de l'espace. Paris: Galilèe.

Pino, C. P. (2006). O espaço modo de usar: Georges Perec. Lettres Françaises, 7, 123-134.

Sheringham, M. (2008). Sophie Calle et l'inventoriage dês gestes quotidiens. In B. Formis, Gestes à l'oeuvre (pp. 152 -166). Paris: De L’Incidence Éditeur.

Tadeu, T. (2011). Documentos de identidade. Introducão às teorias do currículo. Belo Horizonte: Autêntica.

Vila-Matas, E. (2011). História abreviada da literatura portátil. São Paulo: CosacNaify.

Zourabichvili, F. (2005, setembro/dezembro). Deleuze e a questão da literalidade. Educação e Sociedade, 26(93), 1.309-1.321.

Submetido à avaliação em 10 de outubro de 2016; aceito para publicação em 22 de novembro de 2016. 